\title{
Updating the Socio-Economic Regional Policy Evaluation in Terms of Environmental, Social and Economic Directions
}

Submitted 30/05/20, $1^{\text {st }}$ revision $12 / 06 / 20,2^{\text {nd }}$ revision $10 / 07 / 20$, accepted $30 / 07 / 20$

\author{
N.V. Poluyanova ${ }^{1}$
}

\begin{abstract}
:
Purpose: The article considers the possibility of the socio-economic regional policy validation based on sustainable development values, which implies priority of environmental and social directions, supplemented by the economic component.

Design/Methodology/Approach: An analytical review of targets in the framework of the economy's "green" model is carried out and the approaches to the alternatives for the socioeconomic policy validation are presented in this article. The author analysed some indicators of the economic, social, and economic spheres of Belgorod Region in comparison with a number of other regions.

Findings: The analysis makes it possible to conclude that the socio-economic policy of Belgorod Region, from the point of view of its evaluation in the context of environmental, social, and economic components, is carried out at a satisfactory level. To create its fullfledged monitoring, it is necessary to constantly measure the selected indicators in the dynamics of the region, as well as regularly make analytical comparisons with other subjects of the Federal district.

Practical implications: The author suggests selecting indicators that characterize the efficiency of socio-economic regional policy directions, such as environmental, social, and economic ones. The approach can be used as the basis for further monitoring, which involves expanding the range of analysed indicators as well as regular calculations and comparisons. Originality/value: The author's approach can become the basis for the development of the regular evaluation of the socio-economic regional policy. This approach is necessary for validating the environmental, social, and economic aspects of the regional policy since the correct evaluation of the ongoing efforts allows to identify problems and take corrective measures in time.
\end{abstract}

Keywords: Socio-economic regional policy, environmental direction, economic direction, social direction, indicators, evaluation.

JEL Codes: R11, R19.

Paper type: Research article.

${ }^{1}$ Belgorod State Research University, Belgorod, Russian Federation, b14v@yandex.ru 


\section{Introduction}

Validating the quality and the efficiency of the regional socio-economic policy has been and will remain relevant for researchers, since the solution, in accordance with the current situation, depends on the standard of life of the society and the development of the region's economy. Thus, the correct evaluation of the ongoing measures allows to identify problems and take corrective measures in time.

Today, according to the general trend to follow the sustainable development goals, it seems necessary to evaluate regional socio-economic policy based not only on the economy, but also considering social and environmental goals (Bondarenko, Efremenko and Guzenko, 2019). Since the economy and the society as a whole are focused on innovative development, it seems reasonable to study the regional production in terms of innovative orientation. It is necessary for this to choose the region for studying and clarifying the socio-economic policy's efficiency.

\section{Materials and Methods}

Validating the socio-economic policy efficiency in the region, we studied the views of researchers on the sustainable development goals, approaches evaluating economic, social, and environmental components. Moreover, on the material of official statistics, the author compared a number of indicators of environmental, economic, and social well-being of Belgorod Region with a number of other subjects of the Russian Federation. For the investigation of the object under study the author used methods of scientific knowledge such as the description of economic phenomena, the system and comparative analysis, the synthesis, and the graphical interpretation of the obtained data.

\section{Results and Discussion}

The sustainable development is associated with the transition from the "brown" model of managing to the "green" one, in which the following three key areas are differentiated: economic, environmental, and social one. Moreover, in this combination, priority directions are environmental and social (Lyaskovskaya and Grigorieva, 2018). This arrangement of priorities is necessary, since a different trajectory of events in the nearest future may lead to a collapse for humanity (Lyaskovskaya, 2017).

According to most experts it is important to find a balance in the combination of these directions (Pakhomova, Richter and Malyshkov, 2014). In the context of regional development, these data are also valid in terms of focusing on the evaluation of social, environmental, and ecological trends (Podprugin, 2012). Describing the researchers' views on evaluating socio-economic policy in the region, it can be noted that a number of experts focussed on economic indicators (Valitova and Tambovtsev, 2005; Badina, 2012; Mikheeva and Ananyeva, 2011). Researchers analyse the socio-economic 
component in relation to various spheres of the economy (Voronov and Serikov, 2007). A number of scientists focus their attention on identifying the role of the environmental direction in the socio-economic policy in the region (Asilova, 2014; Murzin and Murzina, 2017). Many scientists are interested in the "green" environmental direction (Bondarenko et al., 2018).

However, there is a point of view that when validating socio-economic policy in the region, the environmental, social, and economic components should be evaluated (Popova, 2018). We agree with Popova's views and we make our research based on this expert's opinion (Popova, 2018). We believe that in order to validate the regional socio-economic policy efficiency, it is necessary to identify indicators that make it possible to characterize changes in the environmental, social, and economic spheres.

Figure 1. Dynamics of costs on the environmental protection in a number of regions of the Central Federal district in comparison with indicators for the Russian Federation as a whole in 2015-2018, million rubles.

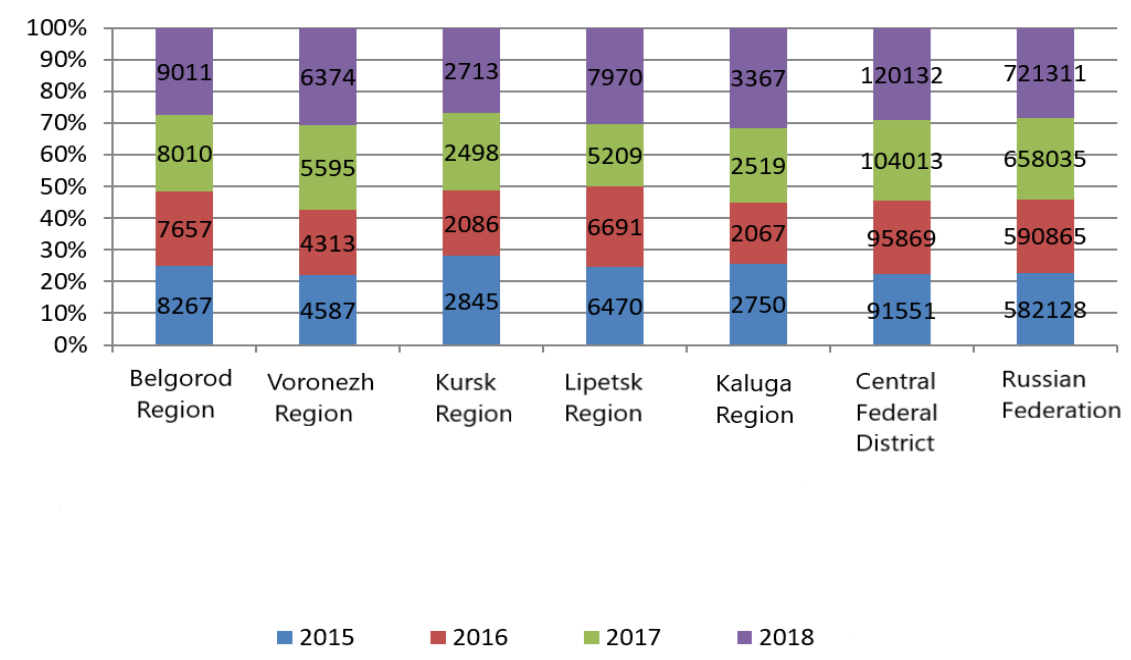

Source: Regions of Russia, 2019.

Investigating the socio-economic policy efficiency in Belgorod Region on the environmental direction, we will analyse the costs of environmental protection and the proportion of captured harmful emissions to the atmosphere in the total volume of emissions.

The costs of environmental protection in Belgorod Region, as well as in a number of other regions of the Central Federal district in comparison with its aggregate indicators and the data of the Russian Federation as a whole are shown in Figure 1. 
Notable that during this period, environmental protection costs in Belgorod Region increased almost by $9 \%$. Belgorod Region accounts for $7.5 \%$ of costs on these needs from all the investments in these environmental measures in the Central Federal district. Also, Belgorod Region is the leader in this indicator among the other four listed subjects of this district.

The data describing the share of captured and neutralized air pollutants in the total amount of waste pollutants from stationary sources in a number of regions of the Central Federal district in comparison with the indicators for the Russian Federation as a whole are shown in Figure 2.

According to the presented analytical information, it can be concluded that Belgorod Region exceeds the all-Russian results and the average results for the Central Federal district in this indicator. However, it is inferior to two of the other four regions shown on the chart, namely Lipetsk and Kaluga.

Figure 2. Dynamics of the share of captured and neutralized air pollutants in the total amount of waste pollutants from stationary sources in a number of regions of the Central Federal district in comparison with indicators for the Russian Federation as a whole in 2015-2018, \%.

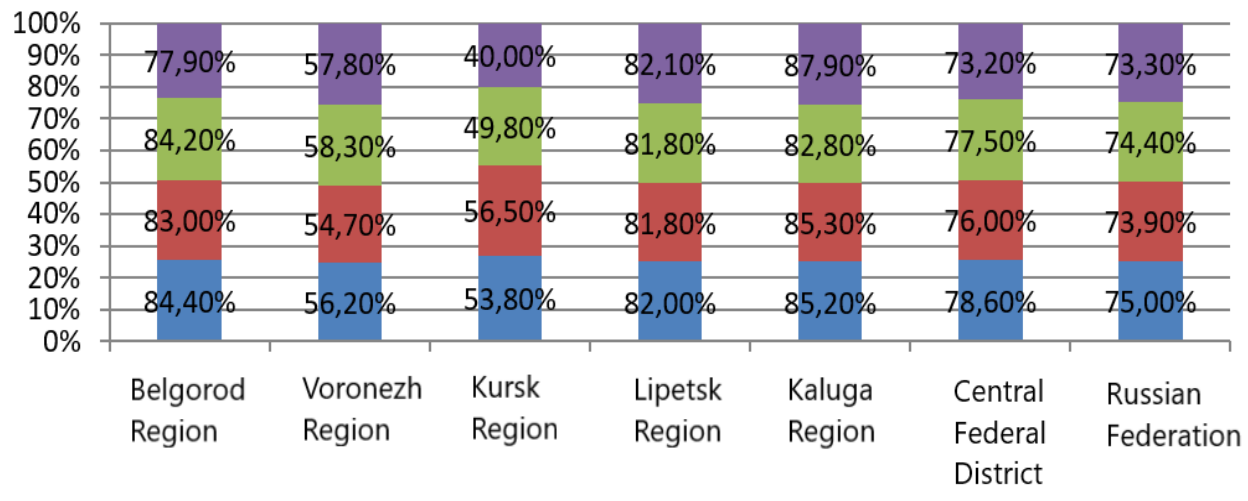

$$
\text { - } 2015 \quad 2016 \quad \text { - } 2017 \quad 2018
$$

Source: Regions of Russia, 2019.

As part of the evaluation of the social sphere associated with the environmental one, in the study of the socio-economic policy's efficiency in Belgorod Region, we should present a situation on the dynamics of respiratory diseases and neoplasms. Dynamics of respiratory diseases in a number of regions of the Central Federal district, along with the average indicator for the Russian Federation as a whole, in 2015-2017 per 1000 people is shown in Figure 3. 
Figure 3. Dynamics of respiratory diseases in a number of regions of the Central Federal district, along with the average indicator for the Russian Federation, as a whole, in 2015-2017 per 1000 people.

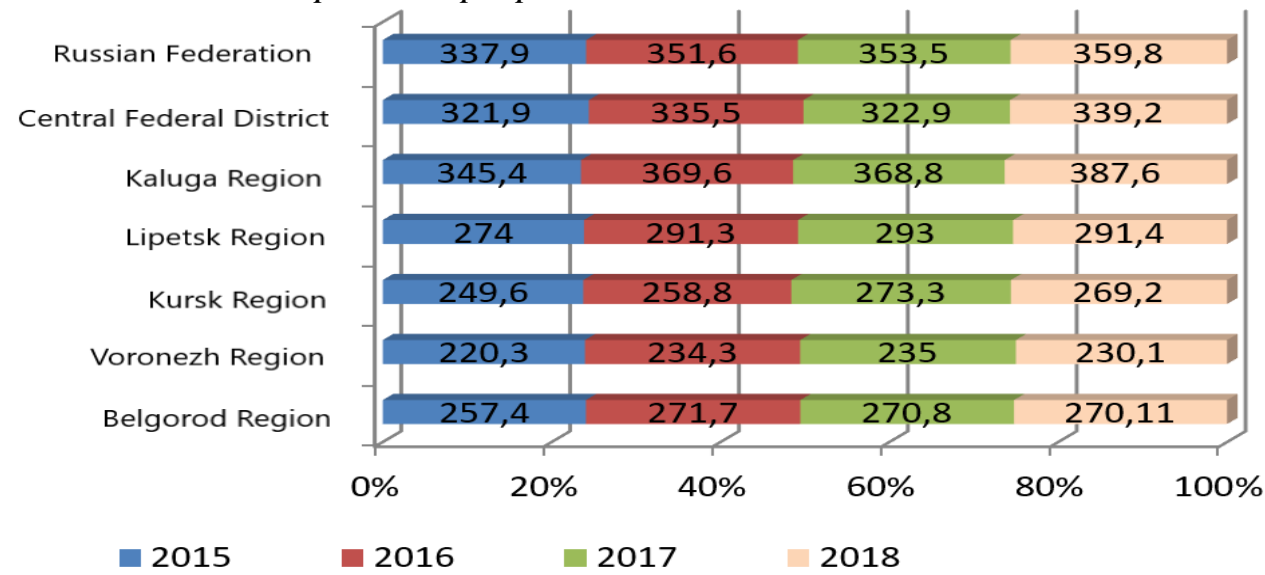

Source: Regions of Russia, 2019.

According to the analytical data, Belgorod Region in this indicator takes the second place after Voronezh Region. Respiratory diseases in Belgorod Region is almost 20\% lower than the average indicator for the Central Federal district, and almost 25\% lower than the national average. Dynamics of neoplasms in the population in a number of regions of the Central Federal district, along with the average indicator for the Russian Federation, as a whole, in 2015-2017 per 1000 people is shown in Figure 4.

Figure 4. Dynamics of neoplasms in the population in a number of regions of the Central Federal district, along with the average indicator for the Russian Federation as a whole, in 2015-2017 per 1000 people.

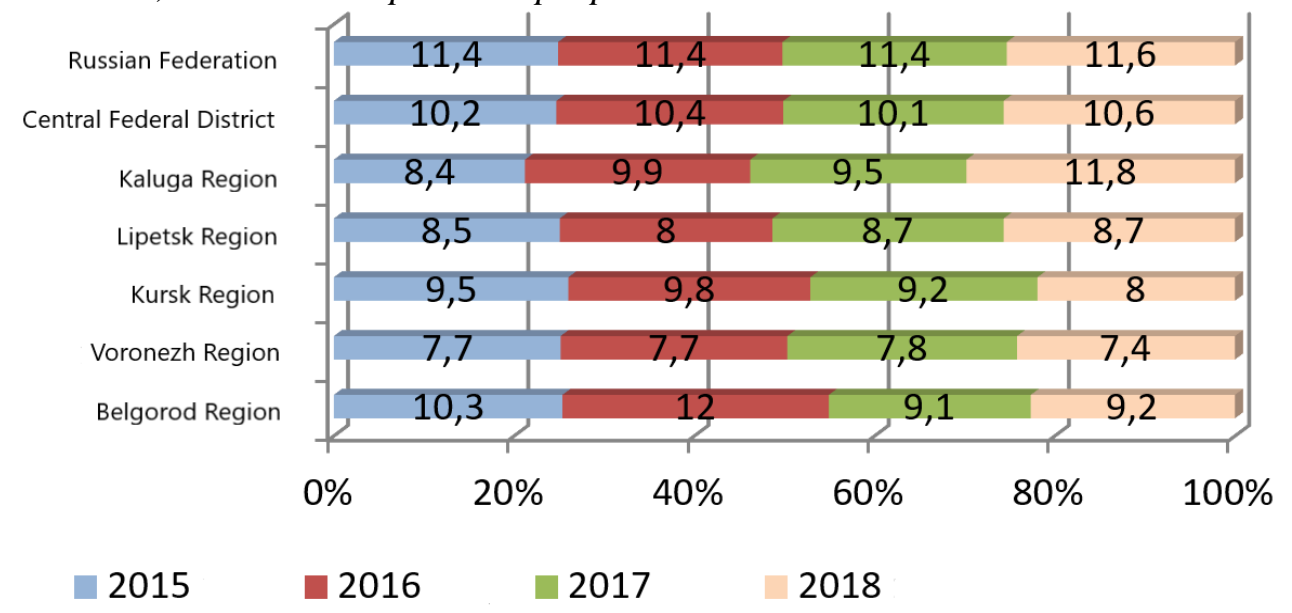

Source: Regions of Russia, 2019. 
According to the dynamics of neoplasms per 1000 people the situation in 2018 in Belgorod Region is better than the average indicator for the Central Federal district and Russia, but the regions listed for comparison, except Kaluga, show a more positive situation.

Figure 5. Dynamics of GRP per capita in a number of regions of the Central Federal district, along with the average indicator for the Russian Federation as a whole, in 2015-2017, rubles.

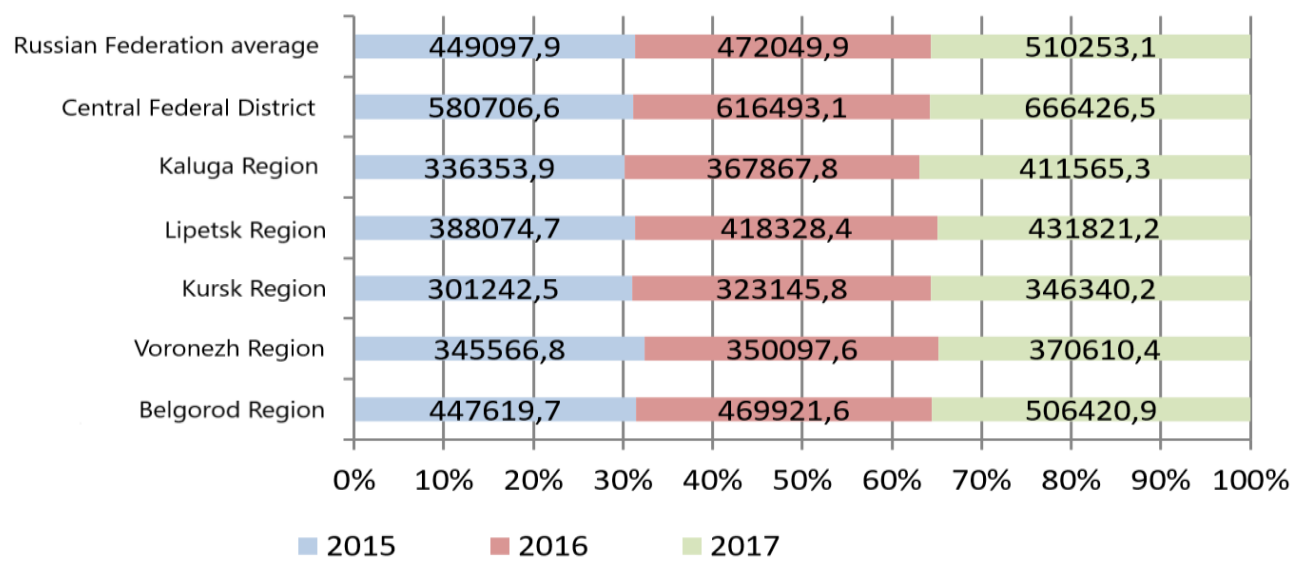

Source: Regions of Russia, 2019.

The comparative data on the dynamics of GRP per capita, depreciation of fixed assets and the volume of innovative products are presented in relation to the evaluation of the economic efficiency of the socio-economic policy in Belgorod Region.

The dynamics of GRP per capita in a number of regions of the Central Federal district, along with indicators for the Russian Federation as a whole, is shown below in Figure 5. During the analysed period, GRP per capita increased in all the represented subjects. In Belgorod region the growth was about 13\%. The change in the depreciation of fixed assets in the analysed subjects is shown in Figure 6.

The depreciation rate for fixed assets in Russia exceeded 50\% in 2018, while the average indicator for the Central Federal district was less than 42\%. Belgorod Region, respectively, is inferior to it, as well as to the results of Voronezh and Kaluga Regions.

Information about changes in the volume of innovative goods, works and services produced in their total volume is shown in Figure 7.

According to the analytical data, it can be concluded that Belgorod Region is the leader in terms of the share of innovative products in the total volume of goods and services in comparison with the other regions in the table, the averaged data for the Central Federal district and the averaged data for the Russian Federation. This indicator is significant now since the economy is innovation oriented. 
Figure 6. Dynamics of the depreciation of fixed assets in a number of regions of the Central Federal district, along with the average indicator for the Russian Federation, as a whole, in 2015-2017, \%.

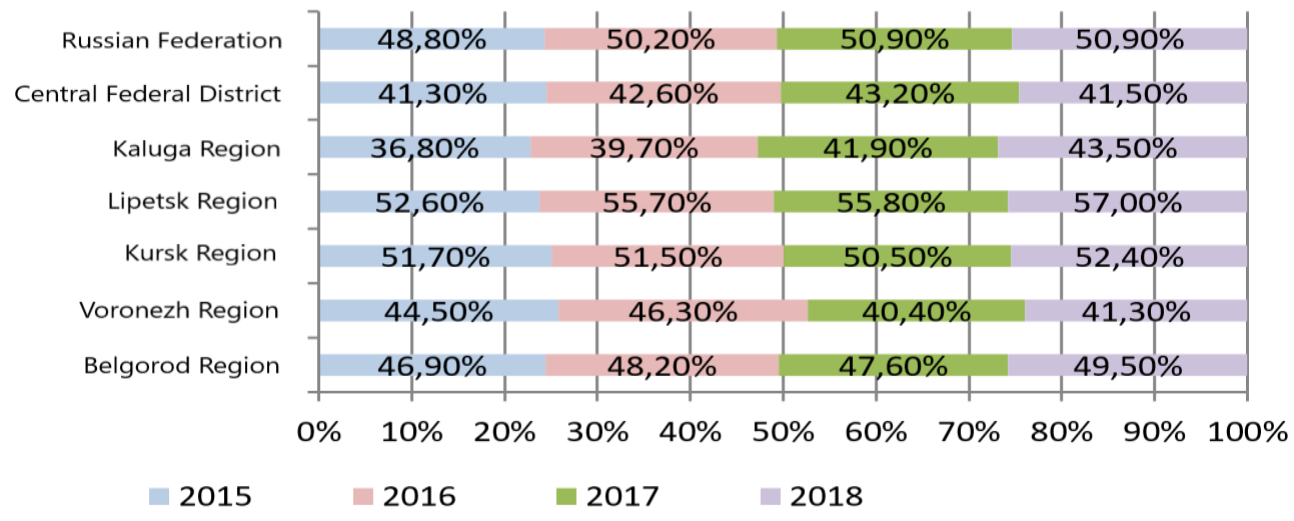

Source: Regions of Russia, 2019.

Figure 7. Dynamics of the volume of innovative goods, works and services produced in their total volume in a number of regions of the Central Federal district, along with the average indicator for the Russian Federation as a whole in 2015-2017, \%.

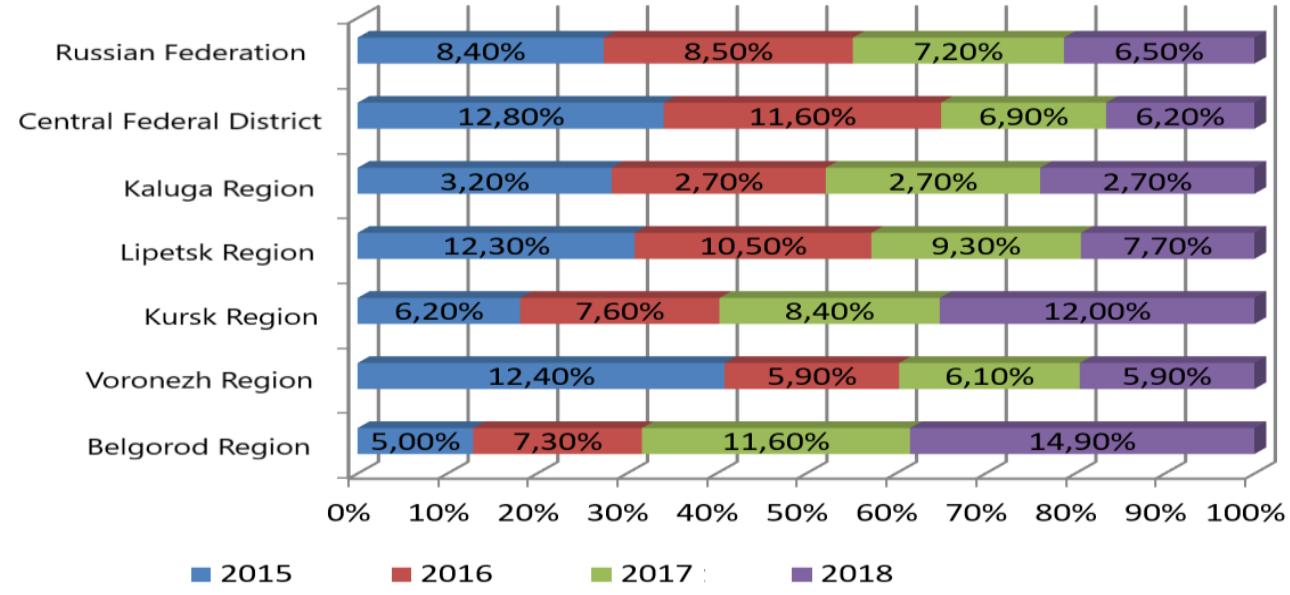

Source: Regions of Russia, 2019.

According to the analysis the socio-economic policy in Belgorod Region, from the point of view of its evaluation in the context of environmental, social, and economic components, is carried out at the satisfactory level. To create a full-fledged monitoring of its implementation, it is necessary to constantly measure the selected indicators in the dynamics of the region, as well as to make analytical comparisons with other subjects of the federal district.

\section{Conclusion}


In the current situation, characterized by the orientation of socio-economic systems on the sustainable development goals, manifested on a global scale, this benchmark value should be the most important in the regional socio-economic policy evaluation.

In this connection it is necessary to validate the ongoing efforts in the environmental, social, and economic areas. We have defined a "narrow" list of indicators for which Belgorod Region was compared with a number of other subjects in terms of evaluating its socio-economic policy. According to the results of our analysis the socio-economic policy and the corresponding changes in the region have had a satisfactory impact. However, we believe that for further monitoring, it is necessary to expand the range of analysed indicators as well as regular calculations and comparisons.

\section{References:}

Asilova, N.N. 2014. The analysis of the decoupling effect in ecological and economic activity of the region. Regional economy: theory and practice, 39(366), 54-61.

Badina, T.E. 2012.The efficiency of state regional policy and ways to increase it. Bulletin of the Buryat State University, 6, 168-172.

Bondarenko, V.A., Dianova, S.N., Joom, T.A., Dubinina, M.A. 2018.

Residents' interest to form a "green" territory brand.

European Research Studies Journal, S1(21), 51-62.

Bondarenko, V.A., Efremenko, I.N., Guzenko, N.V. 2019. Issues of theoretical substantiation of the green economy formation and its prospects for Russia. Financial research, 2(63), 23-31.

Lyaskovskaya, E.A. 2017. Problems of training high-quality labor resources in the implementation of the sustainable and innovative development conception. Bulletin of the Bashkir State Agrarian University, 4(44), 137-145.

Lyaskovskaya, E.A., Grigorieva, K.A. 2018. The green economy formation and the sustainable development of the country and regions. Bulletin of SUSU, Series "Economics and management", 1(12), 15-22.

Mikheeva, N.N., Ananyeva, R.I. 2011. Tools of regional policy: the evaluation of the efficiency. Region: Economics and Sociology, 3, 39-87.

Murzin, A.D., Murzina, S.M. 2017. The analysis of the practice of implementing regional environmental programs in Russia and abroad. Economy and ecology of territorial formations, 1(2), 124-133.

Pakhomova, N.V., Richter, K.K., Malyshkov, G.B. 2014. The inclusive sustainable growth: priorities, indicators. International experience, the potential for harmonization with the model of reindustrialization. Problems of the modern economy, 3(51), 15-24.

Podprugin, M.O. 2012. The sustainable development of the region: concept, main approaches, and factors. Russian entrepreneurship, 24(222), 214-221.

Popova, A.G. 2018. On the issue of evaluating the efficiency of regional policy as a set of economic, social, and environmental components. Regional Economics and Management: electronic scientific journal, 2(54).

Regions of Russia. 2019. Socio-economic indicators. Statistical yearbook, Moscow, Rosstat, 1204. 
Valitova, L.A., Tambovtsev, V.L. 2005. Priorities of the regional policy in Russia: an empirical analysis. Available online:

http://www.recep.ru/files/documents/policy_priorities_ru.pdf.

Voronov, A.A., Serikov, D.V. 2007. The necessity and goals of restructuring industrial enterprises of the construction complex at the present stage of socio-economic development. Economic Bulletin of the Southern Federal district, 6, 116-125. 